\title{
Cenpestato \\ O frasco quebrado: a bibliografia e a cultura da convergência
}

\author{
Marco Antônio de Almeida \\ Doutor; Universidade de São Paulo, São Paulo, SP, Brasil; \\ marcoaa@ffclrp.usp.br
}

Resumo: O artigo propõe uma releitura de "Bibliografia e Sociologia dos Textos" de D. F. McKenzie, estabelecendo conexões com os desafios e perspectivas do presente três décadas após sua publicação. Dois pontos são destacados: 1- a compreensão da bibliografia como uma "sociologia dos textos" - uma área voltada à análise histórica dos processos sociais de produção, circulação e recepção dos textos e 2- os desafios que se colocam à bibliografia ao interrogar-se acerca dos textos que transcendem ao suporte tradicional do livro. As conexões são estabelecidas a partir do território específico das Histórias em Quadrinhos, que ancora empiricamente as reflexões, por meio de dois fios condutores: 1- a ideia de representação social, o processo pelo qual os membros de uma cultura usam a linguagem para produzir sentido e conhecimento; 2- o conceito de "cultura da convergência", focando os processos de apropriação social do conhecimento e da informação. Retomam-se discussões mais amplas sobre identidades sociais e culturais e suas representações nos meios de comunicação, bem como os processos de produção, circulação e apropriação dos textos. O artigo mescla revisão bibliográfica e ensaio teórico com base em discussão da literatura e observação in loco de campo, colocando em diálogo a obra de McKenzie com autores que abordam contemporaneamente os processos tecnoculturais. Ao final da discussão, levantamos um conjunto de coordenadas teóricas e temáticas para contribuir com a atualização e ampliação do escopo do campo de pertinência da bibliografia perante os desafios culturais do mundo atual.

Palavras-chave: Bibliografia. Textos. Cultura da Convergência. Histórias em Quadrinhos. Circulação da Informação.

\section{Introdução}

Em Bibliografia e a Sociologia dos Textos, D. F. McKenzie (2018) aborda o campo da bibliografia, contrapondo ao seu escopo tradicional uma visão mais ampla, voltada para as mutações contemporâneas dos textos. Para ele, a aceleração dos processos históricos pelos quais os textos mudam sua forma e conteúdo teriam tornado praticamente impossível a definição e a localização 
textual ao velho estilo. Bibliografia e a sociologia dos textos levanta pelo menos dois pontos com os quais o campo da Ciência da Informação deveria dialogar. O primeiro diz respeito à compreensão da bibliografia como uma sociologia dos textos - ou seja, como uma área científica voltada à análise histórica dos processos sociais de produção, circulação e recepção dos textos. O segundo ponto, decorrente do anterior, debruça-se sobre os desafios que se colocam à bibliografia ao interrogar-se acerca dos textos que transcendem ao suporte tradicional do livro, ampliando e tornando mais complexa a própria noção de texto. Estes dois pontos levantam questões particularmente relevantes no momento atual, marcado tanto pela presença cada vez maior das tecnologias de comunicação e informação (TICs) no cotidiano dos indivíduos, grupos e instituições como pela multiplicação exponencial de textos nos mais diversos suportes, proporcionada pelos processos de digitalização. Decorre daí tanto questões de ordem teórico-conceitual - como a própria definição do conceito de texto, discussão interdisciplinar por natureza - como questões de ordem metodológica e até instrumental, envolvendo as especificidades técnicas e de linguagem relativas aos novos meios e suportes. Estes desafios e perspectivas vislumbrados por McKenzie, decorridas três décadas de cibercultura desde que ele ministrou suas conferências, permanecem profundamente atuais.

Neste artigo buscamos estabelecer algumas conexões entre estas questões e os processos socioculturais contemporâneos, marcados fortemente pela presença das TICs no cotidiano de nossas sociedades. Escolhemos o território específico das Histórias em Quadrinhos (HQs) para ancorar essas reflexões. Dois fios condutores conduzem a argumentação. O primeiro fio é a apropriação do conceito de representação social - o processo pelo qual os membros de uma cultura se utilizam da linguagem para produzir sentidos e conhecimentos compartilháveis (HALL, 2016). O segundo fio é a concepção de uma "cultura da convergência", focando os processos de apropriação social do conhecimento e da informação. Estes dois conceitos permitem-nos retomar discussões mais amplas acerca das identidades sociais e culturais e suas representações nos meios de comunicação, bem como os processos de produção, circulação e apropriação dos textos. Trata-se de uma reflexão de matriz mais 
teórica, embora baseada em revisão bibliográfica, discussão da literatura e observação de campo. O que procuramos fazer é colocar em diálogo a obra de McKenzie com autores que abordam contemporaneamente os processos tecnoculturais de circulação e apropriação dos textos. Ao final da discussão, esperamos reunir algumas coordenadas teóricas e temáticas para contribuir com a atualização e ampliação do escopo do campo de pertinência da bibliografia perante os desafios culturais do mundo atual.

\section{A "Bibliografia e a Sociologia dos Textos"}

A obra, publicada em inglês no ano da morte de McKenzie (1999), reúne conferências por ele proferidas na década de 80 , e estrutura-se em duas partes. A primeira, dividida em três capítulos, reúne a transcrição das conferências realizadas pelo autor, na British Library, sobre o escopo e os desafios da bibliografia. A segunda parte compreende outra conferência, proferida na Bibliographical Society, acerca da oralidade e do letramento no país de origem do autor, a Nova Zelândia. Vamos nos deter sobre a primeira parte, cujo conjunto propõe analisar o desenvolvimento da bibliografia histórica como campo de estudo, e como as mudanças da contemporaneidade a afetam. Nas próprias palavras do autor, a aceitação da bibliografia histórica no atual momento "[...] sinaliza uma mudança, parcial mas significativa, de questões de autoridade de texto para aquelas de disseminação e leitura enquanto questões de razão política e econômica.” (MCKENZIE, 2018, p. 11). Nesse sentido, os capítulos acompanham a consolidação do livro como forma expressiva, passando pela migração dos textos para outros formatos, proporcionada pelas revoluções advindas nas mudanças tecnológicas no campo da comunicação, concluindo com considerações acerca das características da dialética da bibliografia na atualidade.

No primeiro capítulo, "O livro como uma forma expressiva", a materialidade do livro é discutida num sentido diferente dos paradigmas tradicionais da bibliografia (voltados fundamentalmente para a descrição e catalogação dos impressos), centrando-se em seu potencial discursivo. Embora valorize a bibliografia física - "o estudo de signos que constituem textos e os 
materiais nos quais eles são registrados" - como um ponto de partida importante, considera-a, entretanto, como incapaz de definir a disciplina, visto que "não tem os meios adequados para representar os processos, as dinâmicas técnicas e sociais de transmissão e recepção de um leitor ou de todo um mercado deles." (MCKENZIE, 2018, p. 29). Desse modo, uma "sociologia dos textos" contrastaria com uma bibliografia mais ortodoxa, confinada à inferência lógica estabelecida a partir de signos impressos como marcas meramente arbitrárias.

Em "O frasco quebrado: textos fora dos livros", capítulo que nos interessa mais de perto, o autor propõe uma ampliação do conceito de textualidade e de materialidade da escrita para uma multiplicidade de suportes, questionando ao mesmo tempo a ideia de livro (e, consequentemente, de escrita) como portador ou instrumento da verdade. McKenzie mostra a crescente dificuldade de estabelecer o princípio bibliográfico em formas que não são livros. Desse modo, propõe uma abordagem mais indicativa e pragmática, traçando paralelismos em registros que possuem uma função textual, sujeitos a algum tipo de "controle bibliográfico", que envolvem interpretação e análise histórica. Partindo deste propósito, seria mais útil "pensar simplesmente em termos de homologias, de estruturas correspondentes, sugerindo que, qualquer que seja nosso campo específico - livros, mapas, impressos, tradições orais, teatro, filmes, televisão ou databases de computador - notamos certas questões comuns.” (MCKENZIE, 2018, p. 59) Ao considerar esse pressuposto, o autor traça interessantes reflexões e paralelismos com textos dispostos nessas linguagens e suportes tão distintos, passeando pelos mapas ferroviários e climáticos, mitos aborígenes, peças teatrais e adaptações de Shakespeare para os quadrinhos, dialogando com autores como Christian Metz ou Roland Barthes.

$\mathrm{O}$ autor retoma a distinção entre os dois conceitos de texto expostos nas palestras precedentes na transcrição da terceira conferência, "A dialética da bibliografia atual": um conceito de texto sancionado pelo autor, controlável e definível historicamente, e outro, incompleto, instável, passível de mudanças por seus leitores, intérpretes ou públicos. Embora não haja referências, aqui é perceptível uma notável semelhança com o conceito de "obra aberta" de Umberto Eco (2016). McKenzie enfatiza e aprofunda a discussão entre forma e 
conteúdo, buscando refletir acerca de novos caminhos para que os objetos da escrita possam ser pensados de forma mais ampla. Por meio de um conjunto de observações sobre a natureza da bibliografia e sua relação com os textos, conclui que o desafio para os bibliógrafos - definir os modos de uso dos textos, sua estrutura de ordenação e os futuros estudos que poderiam demandar - estava além do que o campo poderia oferecer naquele momento - meados da década de 80. Em suas próprias palavras, "o que precisamos é nada menos do que um novo conceito do texto na história". (MCKENZIE, 2018, p. 103)

A obra de McKenzie permanece atual, com a força decorrente de sua perspectiva marcadamente interdisciplinar, que abre possibilidades de diálogos com diversas áreas de pesquisa e suas decorrentes problematizações. Nesse sentido, propomos dois possíveis diálogos. O primeiro seria com Stuart Hall (1997, 2016) e sua concepção de representação social, por onde compreende o processo pelo qual os membros de uma cultura usam a linguagem para produzir sentido e conhecimento. Trata-se de uma abordagem construtivista apoiada em uma vertente semiótica/semiológica, influenciada por Saussure e Barthes, concentrada na maneira pela qual os signos produzem sentidos, e em outra vertente, mais discursiva, influenciada por Foucault, focada em como o discurso e as práticas discursivas produzem conhecimentos. As considerações acerca das concepções de texto propostas por McKenzie encontrariam aqui um terreno fértil para desdobrar-se e aprofundar-se. O outro diálogo possível seria com o pesquisador estadunidense Henry Jenkins (2009) e suas concepções acerca de uma "cultura da convergência". As ideias de Jenkins possibilitariam, no caso, reforçar particularmente as conexões entre os processos que caracterizam essa “cultura da convergência" e os processos tecnologicamente mediados de apropriação social do conhecimento e da informação. São perspectivas que, embora formuladas em âmbitos muito distintos, retomam as discussões mais amplas sobre identidades sociais e culturais, bem como os processos de produção, circulação e apropriação dos textos. Esses diálogos potenciais, ao apontarem um conjunto de coordenadas teóricas e temáticas, permitem contribuir com a atualização e ampliação do escopo do campo de pertinência da 
bibliografia perante os desafios culturais da contemporaneidade, só reforçando a atualidade da discussão proposta por McKenzie.

\section{A Cultura da Convergência e o caso das Histórias em Quadrinhos}

Embora a ideia de uma cultura da convergência seja pertinente como descrição de um processo cultural global envolvendo a apropriação cultural mediada pelas tecnologias, características e condições decorrentes das especificidades locais influenciam essa dinâmica. A diversidade de conteúdos e formatos disponíveis nas redes infocomunicacionais, somadas às facilidades proporcionadas pelo formato digital para sua manipulação e reconfiguração possibilitam a hibridização e a recriação cultural por parte dos indivíduos e grupos, gerando distintas possibilidades de apropriação cultural no âmbito de uma cultura da convergência. Henry Jenkins (2009) entende a cultura da convergência como o sistema que envolve fluxo de conteúdos por meio de múltiplas plataformas de mídia, cooperação de mercados midiáticos e comportamento migratório dos públicos. Envolve, portanto, "três conceitos - convergência dos meios de comunicação, cultura participativa e inteligência coletiva”. (JENKINS, 2009, p. 29). O autor enfatiza, em suas análises, que os papéis de "consumidor" e "produtor" seriam, hoje, intercambiáveis de acordo com os contextos e as circunstâncias, cunhando o neologismo "prosumer" para descrever esta situação. Resumidamente, ele argumenta que as atuais ferramentas tecnológicas possibilitariam aos consumidores tornarem-se também produtores de conteúdos. Entre outras consequências dessa nova dinâmica cultural, podemos verificar a estruturação de condições que permitem a emergência e a sustentação de culturas especializadas ou culturas de "nicho".

O objeto e o recorte que propomos para investigar inicialmente essas questões é o universo cultural das Histórias em Quadrinhos (HQs) e a comunidade geek (neologismo que descreve o conjunto de indivíduos interessados nas HQs e produtos derivados como filmes, séries, videogames, etc.) que se estrutura em torno delas. Trata-se de um objeto estratégico do ponto de vista heurístico, na medida em que possibilita a análise e a problematização de questões práticas e teóricas. Muitos autores contemporâneos de HQs 
refletiram acerca da maneira pela qual as tecnologias moldam determinados aspectos das relações de sociabilidade e de poder, como pode ser lido em diversas graphic novels. Na década de 1980, a televisão, por exemplo, é onipresente nas narrativas de Frank Miller como O Cavaleiro das Trevas e Elektra Assassina, cumprindo um papel de conectar a ação dos heróis à sociedade mais ampla e mostrando a maneira pela qual as informações são produzidas e manipuladas. Também Alan Moore, em $V$ de Vingança e Watchmen, reflete acerca da maneira pela qual as tecnologias são determinantes na constituição de uma sociedade da vigilância, que controla e manipula informações de seus cidadãos. Mais contemporaneamente, um dos autores cuja obra é caracterizada por este tipo de reflexão é Warren Ellis, que desenvolve e explora a velha máxima de que "informação é poder", mostrando seu valor e as dificuldades para acessar e controlar as informações de estratégias. Nesse sentido, ele antecipa temas caros à sociedade da informação e à cibercultura, como os conceitos de informação em rede e inteligência coletiva. Ao mesmo tempo, Ellis também filia-se a uma estética "pós-moderna", caracterizada pela linguagem autorreferencial, desconstruindo clichês de gênero e, simultaneamente, recuperando informações e referências históricas da cultura "pop". Essa intertextualidade irá refletir-se não apenas nas construções narrativas, mas também na própria edição das obras, permitindo-nos construir algumas hipóteses acerca dos "regimes de leitura" que elas sinalizam. Reforçando o diálogo com as reflexões de McKenzie, no tocante à edição das obras, multiplicam-se os materiais paratextuais que, segundo Genette (2009), seria o conjunto de elementos que circundam o texto - incluindo não apenas os elementos pré-textuais e pós-textuais, como a própria rede dos comentários, característicos da crítica ou fora do âmbito dela, incluídos ou não no suporte da obra. Este ponto será abordado na próxima seção; no momento, interessa-nos discutir os aspectos mais propriamente adstritos ao território da linguagem.

Os procedimentos de intertextualidade e autoreferencialidade presentes na obra de Ellis estão bem representados em sua obra Planetary (publicado de forma irregular entre 1999-2006, com um episódio de conclusão lançado apenas em 2009). O Planetary é uma organização que se autodefine como 
"Arqueólogos do Impossível", buscando levantar os dados e informações relacionados à "história secreta" do mundo. A equipe é formada por três personagens: Jakita Wagner, uma mulher com características sobre-humanas de força e rapidez; o Baterista, um jovem capaz de conversar com computadores e quaisquer outros tipos de mecanismos eletrônicos, praticamente uma interface viva da informação; e Elijah Snow, capaz de controlar a temperatura e aparentemente recém-chegado ao grupo, mas que posteriormente se revela o misterioso "quarto homem" que dirige secretamente a organização.

Os componentes do Planetary viajam ao redor do globo investigando fenômenos fora do comum: monstros e criaturas do gênero, relíquias misteriosas, outros superseres e segredos estratégicos que permanecem ocultos do resto do mundo. Essa busca é mobilizada em parte pela curiosidade e em parte pela utilidade que esses conhecimentos teriam em prol da humanidade. Sua máxima: "Esse é um mundo estranho e pretendemos mantê-lo assim". O Planetary possui antagonistas que se opõem aos seus propósitos, cuja história se entrelaça com a deles próprios e que vai sendo revelada gradualmente durante a série. Essa dimensão narrativa ganha maior destaque nos últimos episódios da saga e o enredo torna-se cada vez mais relacionado ao enfrentamento com esse grupo, "Os Quatro" (uma versão “em negativo” do “Quarteto Fantástico”, grupo de super-heróis da editora Marvel Comics), cujos objetivos são exatamente opostos.

Planetary traz temas caros a Ellis, encenando a questão do conhecimento e da informação na sua própria arquitetura narrativa e visual. No conjunto, a obra pode ser vista ao mesmo tempo como um tributo e como um compêndio da cultura pop do século XX, trazendo referências não só ao universo das HQs, como também às revistas pulp, à literatura popular, ao cinema oriental de monstros e filmes de gângsteres de Hong Kong, à contracultura lisérgica, às teorias da conspiração, etc. Cada edição se constrói a partir de um conjunto de referências às histórias dessa cultura pop do Século 20, passeando pelas diversas linguagens e meios, adaptando-os à linguagem das HQs. Para tanto, Ellis recorre desbragadamente ao artifício de mesclar gêneros e personagens-citação - 
aqueles que se assemelham a outros muitos conhecidos, e que embora reconhecíveis, não se confundem com os mesmos.

$\mathrm{Na} 13^{\mathrm{a}}$ edição, um bom exemplo desses procedimentos, temos um episódio que é uma homenagem à literatura de final do século XIX, a autores como H.G. Wells, Júlio Verne e Conan Doyle, referências para o que ocorre na trama. Por meio de um flashback do começo do Século XX, vemos o encontro de Snow com o grupo que tentou controlar o mundo no Século XIX, formado pelos personagens da literatura popular vitoriana: Frankenstein, Drácula, Sherlock Holmes, Homem Invisível, criaturas reptilianas, entre outros. No desenlace da trama, Elijah Snow torna-se o pupilo de um Sherlock Holmes já ancião, instituindo-se como continuador de sua linhagem, mas com suas próprias características - um ator dos acontecimentos, que une o conhecimento à ação.

Este tipo de narrativa, que demanda uma quantidade substancial de informações e repertório cultural por parte do leitor, está intrinsecamente ligada a um conjunto de mudanças no mundo das HQs, que envolve conteúdos e linguagens, bem como formatos (graphic novels, encadernados), formas de circulação (dos produtos, mas também da informação) e de processos de legitimação simbólica (que passa pela constituição de circuitos especializados), o que implica que esse leitor possua um conhecimento enciclopédico cada vez mais amplo. O conceito de enciclopédia ou de conhecimento enciclopédico poderia ser traduzido, em outras palavras, como o patrimônio cultural (de um indivíduo ou de uma comunidade), que compreende toda a gama de experiências e informações, o conhecimento de convenções, o maior ou menor domínio dos códigos de linguagem, referenciais religiosos, sociais, políticos, etc. Desse modo, nenhum texto (e estamos compreendendo texto aqui no seu caráter mais aberto de produção cultural) pode ser lido independentemente da experiência de outros textos - e o grau dessa experiência determina diferenças substantivas entre os leitores: "As encenações intertextuais, pelo contrário, são esquemas retóricos e narrativos que fazem parte de um repertório selecionado e restrito de conhecimento que nem todos os membros de uma determinada cultura possuem" (ECO, 1986, p. 66). Assim, alguns leitores são vítimas de clichês, 
golpes teatrais, velhos esquemas de suspense ou terror que um leitor mais sofisticado, ao contrário, considera bastante banais, prevendo com mais facilidade o fim da história e, eventualmente, se deleitando com a violação de algumas regras narrativas que quebram as expectativas do leitor comum. $\mathrm{O}$ leitor de HQs encontra-se hoje numa situação semelhante à descrita por Umberto Eco em relação ao espectador de filmes e séries:

Aqui o espectador deve saber muitas coisas [...] deve, em suma, possuir não somente um conhecimento dos textos mas também um conhecimento do mundo, ou seja, das circunstâncias externas aos textos. [...] Antigamente, um fenômeno desse gênero era típico de uma arte experimental que pressupunha um leitor-modelo culturalmente assaz sofisticado. $\mathrm{O}$ fato de tais procedimentos serem sempre mais comuns no universo dos meios de comunicação de massa nos leva a algumas considerações: os mass media se preocupam com - pressupondo-as - informações já veiculadas por outros mass media. (ECO, 1989, p. 127).

A quantidade desse tipo de informação demandada por cada história e pela série como um todo é enorme, sinalizando como leitor ideal aquele tipo de leitor denominado de "leitor de segundo nível" por Umberto Eco, que não está focado exclusivamente no desenrolar da narrativa em si, mas nas referências, apropriações e recriações de que o autor lança mão. Se, no passado, coube à crítica fazer a mediação dessas informações para o público melhor compreender as obras, agora, muitas vezes, a própria crítica se encontra na mesma situação ou - como em alguns casos, dado o desconhecimento de muitos dos críticos sobre esse universo popular massivo do público -, até pior ${ }^{1}$.

No âmbito de uma "sociedade da informação", uma visão de senso comum postularia que o ato de informar-se seria algo bastante prosaico - o que não é verdade. Uma reflexão que se impõe é acerca das estruturas de interpretação utilizadas para passar da recepção das informações à sua apropriação como conhecimento. Nesse sentido, a informação é secundária em relação aos sistemas de conhecimento, aos esquemas de interpretação socioculturais que the atribuem valor e status e que "permitem separar a informação relevante do 'ruído' provocado pelo incessante e sempre crescente fluxo informacional. Cabe interrogar, portanto, de que maneira esses quadros 
simbólicos de interpretação são construídos e compartilhados.” (ALMEIDA, 2009, p. 186).

Nossa hipótese é de que as TICs - especialmente a Internet multiplicaram os canais de expressão dos reviewers, ampliando o espaço de produção e circulação de informações culturais e reconfigurando os circuitos de crítica e mediação. Diariamente surgem cada vez mais sites e blogs dedicados ao cinema, às HQs, aos seriados, sejam de crítica e/ou de informação, produzidos pelos próprios espectadores/leitores. Alguns sites possuem caráter mais geral, outros se especializam em determinados recortes: temas, períodos, gêneros narrativos, origem geográfica, diretores e/ou autores específicos, etc. São fontes importantes de informações para uma melhor compreensão das obras e dos universos culturais nelas referenciados.

Henry Jenkins (2009) afirma que vivemos um momento de colisão entre novas e velhas mídias, entre produtores e receptores. O pensamento convergente lança um olhar particular sobre a cultura popular, reconfigurando as relações entre públicos, produtores e conteúdos da mídia ${ }^{2}$. Este diagnóstico é estabelecido a partir da relação entre três conceitos: convergência dos meios de comunicação, cultura participativa e inteligência coletiva. A convergência dos meios de comunicação não é um fato exclusivamente tecnológico, que ocorreria apenas por meio de aparatos cada vez mais sofisticados - na verdade, a "convergência ocorre dentro dos cérebros de consumidores individuais e em suas interações sociais com os outros" (JENKINS, 2009, p. 30). Indivíduos e grupos constroem seus imaginários próprios, costurando e conectando pedaços e fragmentos de informações extraídas do fluxo midiático, transformando-os em recursos para a compreensão da vida cotidiana. Aqui, o autor recorre ao conceito de "inteligência coletiva" de Pierre Lévy (1998): na medida em que existem mais informações sobre determinado assunto do que um único indivíduo ou grupo possa efetivamente se apropriar, há um incentivo extra para que conversem entre si sobre a mídia que consomem. Para Jenkins (2009, p. 30), “a inteligência coletiva pode ser vista como uma fonte alternativa de poder midiático". O foco maior de Jenkins é nas mudanças de "protocolos", mais que nas mudanças de tecnologia em si: “A convergência envolve uma transformação 
tanto na forma de produzir quanto na forma de consumir os meios de comunicação" (JENKINS, 2009, p. 44).

Ao tecer suas considerações sobre a cultura popular, Jenkins a está concebendo principalmente como o produto da indústria cultural do entretenimento, veiculada e consumida massivamente por meio da mídia. Sua atenção volta-se, basicamente, sobre os efeitos da internet e das redes colaborativas na reconfiguração dos meios de comunicação anteriores. A diversidade de conteúdos e formatos disponíveis nas redes infocomunicacionais, somadas às facilidades proporcionadas pelo formato digital para sua manipulação e reconfiguração possibilitam a hibridização e a recriação cultural por parte dos indivíduos e grupos, gerando distintas possibilidades de apropriação cultural no âmbito de uma cultura da convergência.

Nesse sentido é que Jenkins (apropriando de um conceito cunhado por Alvin Toffler) aponta a emergência da figura do "prosumer" (neologismo oriundo da combinação das palavras "produtor" e "consumidor"). A concepção do "prosumer" parte da constatação de que, potencialmente, os indivíduos na sociedade em rede tornaram-se capazes, com as ferramentas disponíveis, de tornarem-se também produtores de conteúdo. Essa possibilidade estabeleceria um ciclo contínuo entre os papéis de emissores/receptores das mensagens, conferindo-lhes, então, a simultaneidade entre produção e consumo embaralhando, consideravelmente, o que tradicionalmente compreendemos como "usuários". O perfil do "prosumer" tornou-se cada vez mais comum por conta das mídias sociais, gerando com isso um aumento do fenômeno descrito por Chris Anderson (2006) como "cauda longa". Essa consistiria, para ele, na possibilidade das pessoas encontrarem ofertas culturais minoritárias que seriam de seu interesse, mas que em geral não são providas pela indústria de entretenimento - possibilitando, em muitos casos, a emergência de efetivas culturas de "nicho".

E se radicalizarmos o argumento de Anderson, no sentido de compreender a internet como sendo, na verdade, um conjunto de culturas paralelas? As observações de Frédéric Martel (2015) apontam nessa direção. Para ele, a internet promove uma "re-territorialização", na medida em que a web 
seria muito mais local, regional, eventualmente nacional ou transnacional do que propriamente "global". Ele lembra que a expressão "comunidade" (community) em inglês não está necessariamente vinculada a um território específico, podendo remeter ao mesmo tempo a um grupo étnico, uma minoria sexual, uma religião ou a um bairro: “às vezes, esse 'território' assume uma forma linguística ou cultural; reflete então uma comunidade unida por interesses, afinidades ou gostos" (MARTEL, 2015, p. 417).

A construção dessas comunidades ou grupos correlaciona-se a uma circulação e apropriação de informações cada vez mais intensa, muitas vezes além das capacidades e competências dos indivíduos ou coletivos. No limite, demanda-se para a efetiva apropriação dessas informações um conjunto de meta-informações, de informações acerca das próprias informações, que permitam a seleção, priorização e até a incorporação das informações que sejam efetivamente consideradas relevantes pelos indivíduos. É nesse sentido que cabe retomar algumas ideias desenvolvidas por Gerard Genette (2009) que podem ser úteis para refletir acerca dessa dinâmica de circulação-apropriação da informação no mundo contemporâneo, e que se estruturam em torno da concepção de paratextualidade.

\section{Paratextualidade e Circulação da Informação}

A ideia de paratextualidade desenvolvida por Gérard Genette (2009), referida de passagem na seção anterior, considera que o texto geralmente se apresenta reforçado por certo número de produções, sejam elas verbais ou não-verbais que de alguma maneira o cercam e o prolongam, configurando sua presença no mundo, sua "recepção" e seu consumo. Nessa perspectiva o texto é ampliado pelos elementos que o circundam, não só os elementos pré-textuais e póstextuais, mas também a rede de comentários, incluindo o âmbito especializado da crítica e além - entrevistas de autores, matérias jornalísticas, comentários e depoimentos de fãs, etc.

Vale levar em conta aqui a perspectiva de Hjarvard (2014), para o qual o mundo passa por uma midiatização intensa da cultura e da sociedade que não se limita à formação da opinião pública, mas atravessa quase todas as instituições 
sociais e culturais. Desse modo, outras instituições necessitam cada vez mais de recursos da mídia, o que envolve sua habilidade de representar a informação, construir relações sociais e ganhar atenção com ações comunicativas. Hjarvard retira como implicação desse raciocínio que ocorre um impacto na formação dos capitais e competências culturais decorrente da concorrência dos laços fracos ${ }^{3}$ proporcionada pelos meios de comunicação. Como nova forma preferencial de interação na sociedade da informação, reúne tanto elementos racionais como emocionais: "devido à natureza em parte privada, em parte pública da sociabilidade, o reconhecimento por intermédio dos meios de comunicação muitas vezes assume igualmente uma forma emocional e uma forma racional." (HJARVARD, 2014, p. 237) Confluem aqui as ideias de comunidade de gosto, de um lado, e de outro a produção de "estruturas de sentimento", de "formações culturais" (WILLIAMS, 1992), para as quais, na sua configuração contemporânea, a paratextualidade assume um papel estratégico e definidor.

O paratexto é formado por duas modalidades paratextuais: o peritexto e o epitexto (GENETTE, 2009). O peritexto refere-se à uma categoria espacial marcada pela continuidade ou unidade da obra. Os elementos peritextuais circundam o texto dentro do próprio espaço da obra, estando em continuidade direta, como o nome do autor, os títulos e intertítulos e toda materialidade daí advinda, como as indicações de coleção, capa, ilustração etc. O epitexto, por sua vez, também está situado no entorno do texto, porém a uma distância marcada por uma descontinuidade em relação à obra. Os elementos epitextuais são divididos em públicos, os que tomam forma nos suportes midiáticos, como as entrevistas do autor, debates, resenhas etc., e os privados, como correspondências e diários que, com o tempo, podem passar a integrar a obra. Assim, o epitexto é, por excelência, o discurso do mundo, na medida em que ele envolve o livro, o enlaça, mas sem nele se misturar, sendo-lhe totalmente exterior. (GENETTE, 2009)

A ocorrência desse tipo de fenômeno no universo das HQs pode ser ilustrada com a assim denominada "invasão inglesa", que ocorreu a partir dos anos 80 nos EUA e modificou profundamente o estilo das histórias produzidas 
por editoras como a Marvel e a DC Comics. Autores (o termo se justifica, na medida em que são escritores/roteiristas) como Neal Gaiman (Sandman, Livros da Magia), Alan Moore (Watchmen, HellBlazer, Promethea), Grant Morrison (Homem-Animal, Patrulha do Destino, Invisíveis) e o próprio Warren Elllis criaram obras constituídas a partir de um universo de referências e citações internas ao próprio gênero e para além dele, cobrindo a literatura, o cinema, a música, a política e a ciência. As próprias editoras passaram a incorporar a esses trabalhos glossários de termos, guias e textos com comentários para auxiliar o público em sua leitura. Como se isso não bastasse, também as comunidades de fãs/leitores passaram a produzir seus próprios fanzines, sites e blogs para disseminar informações, comentários e críticas acerca das obras.

Como mesmo para esse leitor a quantidade de informações necessárias é muito grande, uma prática que foi se tornando cada vez mais comum foi a criação e a multiplicação de "paratextos" acompanhando as histórias, na forma de glossários, editoriais explicativos, etc, complementados e/ou expandidos nos blogs e sites dedicados ao gênero e mantidos por profissionais e/ou aficionados, e que cada vez se multiplicam mais, sinalizando, em alguma medida, um novo "regime de leitura" instaurado por este tipo de produção cultural. No Brasil, Planetary foi inicialmente publicado na extinta revista Pixel, que dedicou alguns editoriais para comentar a série e esclarecer aspectos da mesma para seus leitores. O procedimento se manteve e se ampliou com as introduções nas edições encadernadas da Editora Devir e nos encadernados da Editora Panini, que reuniram os 27 episódios que compõem a série completa. As demais obras de Ellis, assim como as outras já mencionadas de Miller, Moore, Gaiman, etc. também receberam tratamento semelhante.

A circulação de informações e discussões sobre essas publicações estende-se também aos muitos sites e blogs especializados em HQs, aos fóruns de debates, às páginas das redes sociais como Facebook, Twitter, etc. Nesse sentido, em alguma medida os paratextos também se tornaram uma estratégia comercial, "agregando valor" aos produtos, que são reconfigurados em outros formatos mais "nobres" e de maior custo: encadernados especiais, edições de colecionador, edições históricas, edições “definitivas”, etc. De qualquer modo, 
esse conjunto de práticas culturais - dos produtores, autores, leitores e mediadores especializados (críticos, editores, etc.) sintonizam-se um regime de circulação dos bens simbólicos de uma sociedade da informação marcada pela cultura da convergência.

Esse universo paratextual que orbita em torno da obra não possui, necessariamente, uma regularidade sistemática: existem livros sem prefácio, obras que não geram fortuna crítica, autores refratários a eventos ou entrevistas, etc. As configurações e materializações do paratexto sofrem modificações de acordo com cada época, cultura ou gêneros da narrativa. Em nossa época midiática, a produção de discursos que circundam uma obra multiplicam-se exponencialmente, o que contribui fortemente para a sua divulgação e contribui na constituição de sua matriz de recepção, na formação de protocolos sociais de leitura. Além disso, como já mencionado, esses protocolos de leitura incorporam elementos socioculturais mais amplos, que não se restringem aos códigos internos das obras. No momento atual, esses protocolos também se abrem para as questões de representação identitária, principalmente as que envolvem as populações negras, as mulheres e os grupos LGBT.

\section{Considerações Finais}

Ao considerarmos as práticas culturais disseminadas pelo mundo das HQs formas alternativas de acesso, de viabilização de produções e de sua circulação, da introdução de novas temáticas e de novos protocolos de leitura para as antigas produções -, encontramos sintonia com as observações de Jenkins, quando ele assinala que uma das marcas da convergência das mídias tem sido o deslocamento dos conteúdos produzidos/disseminados por uma cultura midiática na direção de outros suportes e de novas perspectivas de acessibilidade mediante o estabelecimento de relações mais complexas entre as interfaces/produtos e a manifestação participativa de suas audiências. Ao refletir acerca da cultura do fandom (a cultura produzida pelos fãs/amadores para circulação na economia de nicho e/ou underground e que extrai da cultura comercial boa parte de seus conteúdos e referências), percebe-se a mudança da concepção de participação 
para um viés mais ativo, de interação e produção no âmbito das mudanças provocadas pelas tecnologias, na passagem de "uma subcultura particular para um modelo mais amplo que engloba muitos grupos que estão adquirindo maior capacidade de comunicação dentro de uma cultura em rede, e rumo a um contexto em que a produção cultural de nicho está cada vez mais influenciando o formato e a direção da mídia mainstream." (JENKINS, GREEN; FORD, 2014, p. 64). Assim, os papéis desempenhados pelos diversos atores estão cada vez mais complexamente entrelaçados, embaralhando inclusive as perspectivas sobre adesão ou resistência cultural. Ou, como observam os autores, "Estamos passando da celebração do crescimento de oportunidades de participação para uma perspectiva ponderada pela atenção aos obstáculos que impedem muitas pessoas de exercer uma participação significativa." (JENKINS, GREEN; FORD, 3014, p. 65).

Acredito que as práticas observadas em relação ao universo das HQs encontram similaridades em outros territórios culturais. Na Colômbia, as iniciativas dos jovens de bairros populares de Medellín, descritas por Mansilla (2015), configuram territórios híbridos, que se constituem entre o local e o digital, o presencial e o virtual. Os jovens se utilizam dos novos meios proporcionados pela internet para desenvolver certas expressões culturais populares como o hip-hop, a dança e também o grafite e o vídeo. A intersecção dos mundos físico e digital produz um espaço híbrido no qual o acesso é constantemente reformulado, permitindo-lhe uma elevada plasticidade. Os jovens utilizam este espaço para reconfigurar suas percepções de exclusão e consolidar a identidade do grupo frente à complexidade da cidade. Essas iniciativas de grupos jovens, emulando a cultura do fandom, mas visando um circuito mais propriamente underground, também é visível nas periferias das metrópoles brasileiras. Em São Paulo, o coletivo Lentes Periféricas registra diversas iniciativas culturais e de apropriação dos territórios urbanos nas periferias paulistanas. Um exemplo é o filme Cine Campinho (vencedor do concurso audiovisual patrocinado pelo Portal da Juventude da SMC-São Paulo), que narra a iniciativa de jovens de diversos bairros periféricos que 
transformaram um campo abandonado e coberto de lixo em Guaianases em um cinema ao ar livre.

A apropriação dos recursos e interstícios proporcionados pela internet no que tange à geração de formas, conteúdos e identidades proporciona a emergência de repertórios culturais híbridos, que misturam práticas tradicionais e inovadoras, institucionalizadas e não-institucionalizadas, legais e "marginais". Por outro lado, as indústrias culturais e seus braços na internet também atentam para esses processos, procurando se aproveitar deles e, no limite, controlá-los. Tornou-se perceptível, para elas, a necessidade de serem capazes de criar novas necessidades a partir da percepção de como são os fluxos de interesses das pessoas que possuem cada vez mais opções disponíveis para seguir: "a captura das atenções é uma arte, mas uma arte tecnológica, baseada na análise dos comportamentos, na definição de padrões comportamentais dos segmentos e indivíduos em rede" (SILVEIRA, 2016, p. 18). Seguindo o raciocínio de Silveira, as plataformas de comunicação online tornaram-se as mediadoras das ofertas culturais na busca por seus consumidores, buscando modular o comportamento e as escolhas das pessoas por meio dos algoritmos. Nesse sentido, a internet hoje é talvez o front mais ativo da guerra cultural. Estará a bibliografia preparada para participar dessas batalhas? E, em estando, sabe qual lado irá apoiar? Perguntas difíceis num momento bastante nebuloso da história, e que a releitura dos trabalhos de McKenzie permite vislumbrar historicamente algumas linhas de força e de reflexão que podem contribuir para nos trazer alguns pontos de partida para a formulação de respostas.

\section{Referências}

ALMEIDA, M. A. Informação, tecnologia e mediações culturais. Perspectivas em Ciência da Informação, Belo Horizonte, v. 14, número especial, p. 184200, 2009.

ALMEIDA, M. A. Processos culturais \& Convergências tecnosociais. Revista do Centro de Pesquisa e Formação do SESC. São Paulo: SESC, n. 02, 2016, p. 142-158.

ANDERSON, Chris. Cauda longa: do mercado de massa para o mercado de nicho. Rio de Janeiro: Elsevier, 2006. 
ECO, U. Lector in fabula. São Paulo: Perspectiva, 1986.

ECO, U. O texto, o prazer, o consumo; Inovação no seriado. In: Sobre os espelhos e outros ensaios. Rio de Janeiro: Nova Fronteira, 1989, p. 100-109 e 120-139.

ECO, U. Obra Aberta. 10. ed. São Paulo: Perspectiva, 2016.

ELLIS, W. Planetary. Panini Books: Barueri (SP), 2013a (v. 1), 2013b (v. 2), 2014a (v. 3), 2014b (v. 4).

GENETTE, G. Paratextos Editoriais. São Paulo: Ateliê Editorial, 2009.

HALL, S. A centralidade da cultura: notas sobre as revoluções culturais do nosso tempo. Educação \& Realidade, Porto Alegre, v. 22, n. 2, p. 15-46, 1997.

HALL, S. Cultura e Representação. Rio de Janeiro: Ed. PUC-Rio: Apicuri, 2016.

HJARVARD, S. A midiatização da cultura e da sociedade. São Leopoldo: Ed. Unisinos, 2014.

JENKINS, H. Cultura da convergência. São Paulo: Aleph, 2009.

JENKINS, H.; GREEN, J.; FORD, S. Cultura da conexão. São Paulo: Aleph, 2014.

LÉVY, P. Cibercultura. S. Paulo: Editora 34, 1998.

MANSILLA, J. C. Reconfigurando elespacio público, redefiniendo La marginalidad urbana: um estudio de caso conjóvenes de barrios populares de Medellín, Colombia. XI Jornadas de Sociología. Facultad de Ciencias Sociales, Universidad de Buenos Aires, Buenos Aires, 2015. Disponível em: http://www.aacademica.org/000-061/174. Acesso em: 29 nov. 2018.

MARTEL, F. Smart: o que você não sabe sobre a internet. Rio de Janeiro: Civilização Brasileira, 2015.

McKENZIE, D. F. Bibliografia e a Sociologia dos Textos. São Paulo: EDUSP, 2018.

SILVEIRA, S. A. Economia da intrusão e modulação na internet. Liinc em Revista, Rio de Janeiro, v.12, n.1, p. 17-24, maio 2016.

WILLIAMS, R. Cultura. Rio de Janeiro: Paz e Terra, 1992. 


\title{
The broken bottle: the bibliography and the convergence culture
}

\begin{abstract}
The article proposes a re-reading of D. McKenzie's "Bibliography and Sociology of Texts", establishing connections with the challenges and perspectives of the present three decades after its publication. Two points are highlighted: 1- the understanding of bibliography as a "sociology of texts" - an area focused on the historical analysis of the social processes of production, circulation and reception of texts and 2- the challenges that are placed in the bibliography when questioning about the texts that transcend the traditional support of the book. The connections are established from the specific Comics' territory, which empirically anchor the reflections, through two conducting threads: 1- the idea of social representation, the process by which the members of a culture use language to produce meaning and knowledge; 2 - the concept of "culture of convergence", focusing on the processes of social appropriation of knowledge and information. There are broader discussions about social and cultural identities and their representations in the media, as well as the processes of production, circulation and appropriation of texts. The article mixes bibliographic review and theoretical essay based on literature discussion and in loco observation, putting in dialogue the work of McKenzie with authors who approach contemporaneously the technocultural processes. At the end of the discussion, we raised a set of theoretical and thematic coordinates to contribute to the updating and extension of the field of relevance of the bibliography to the cultural challenges of the world today.
\end{abstract}

Keywords: Bibliography. Texts. Convergence Culture. Comics. Information Circulation.

\section{El frasco roto: la bibliografía y la cultura de la convergencia}

Resumen: El artículo propone una relectura de "Bibliografía y Sociología de los Textos" de D. F. McKenzie, estableciendo conexiones con los desafíos y perspectivas del presente tres décadas después de su publicación. Dos puntos son destacados: 1- la comprensión de la bibliografía como una "sociología de los textos" - un área volcada al análisis histórico de los procesos sociales de producción, circulación y recepción de los textos y 2- los desafíos que se plantean a la bibliografía al interrogarse sobre los textos que trascienden al soporte tradicional del libro. Las conexiones se establecen a partir de lo territorio específico de las Historias cómicas, que ancla empíricamente las reflexiones, por medio de dos hilos conductores: 1- la idea de representación social, el proceso por el cual los miembros de una cultura usan el lenguaje para producir sentido y conocimiento; 2- el concepto de "cultura de la convergencia", enfocando los procesos de apropiación social del conocimiento y de la información. Se reanudan discusiones más amplias sobre identidades sociales y culturales y sus representaciones en los medios de comunicación, así como los procesos de producción, circulación y apropiación de los textos. El artículo 
mezcla revisión bibliográfica y ensayo teórico con base en discusión de la literatura y observación in loco campo, poniendo en diálogo la obra de McKenzie con autores que abordan contemporáneamente los procesos tecnoculturales. Al final de la discusión, levantamos un conjunto de coordenadas teóricas y temáticas para contribuir con la actualización y ampliación del alcance del campo de pertinencia de la bibliografía ante los desafíos culturales del mundo actual.

Palabras clave: Bibliografía. Textos. Cultura de la Convergencia. Cómics. Circulación de la Información.

Recebido: 29/04/2019

Aceito: 19/06/2019

1 A essa altura da discussão pode ser esclarecedor considerar a distinção que em inglês é expressa pelos termos critic e reviewer. No caso do critic, o diálogo privilegiado é com os realizadores, com as pessoas que de um modo geral estão ligadas à produção cinematográfica, buscando emitir assim opiniões e conselhos que contribuam para estimular a produção e evitar possíveis equívocos. Já o reviewer, especialmente para os americanos, é a pessoa que escreve textos de natureza crítica com o propósito de orientar seus leitores, relatando suas próprias reações e compartilhando critérios de julgamento pessoal em relação à obra; cumpre, portanto, a função de guia, de comentador. É aqui que entram as novas possibilidades descortinadas pelas TICs.

2 Para uma discussão acerca das diferentes concepções de "cultura popular" tendo em vista o contexto norte-americano de Jenkins e o contexto latino-americano, em especial brasileiro, vide ALMEIDA, 2016.

${ }^{3}$ Um indicador da força social que une os indivíduos é frequência e a duração de suas interações. De um modo geral, os laços sociais fortes são considerados importantes para a coesão geral da sociedade. Hjarvard recupera a afirmação de Granovetter, para quem os laços fracos são superiores aos fortes em certos aspectos, no que diz respeito, por exemplo, à difusão das informações nas redes sociais. Eles permitem alcançar uma quantidade maior de pessoas e percorrer uma maior distância social (no caso, um maior percurso na rede) em comparação com os laços fortes, o que permitiria falar da 'força dos laços fracos' (HJARVARD, 2014). 